\title{
MANAGING AND DELIVERING INFORMATION TECHNOLOGY VALUE
}

\author{
Yuliana Lisanti \\ Jurusan Sistem Informasi, Universitas Bina Nusantara \\ Jln. KH Syahdan No. 9 Kemanggisan Palmerah, Jakarta. \\ lisanti@binus.edu
}

\begin{abstract}
Investment Information Technology (IT) has always been a primary objective of the business which is expected to provide value to businesses through its role as a competitive advantage and the creation of innovation. However, it is ot easy to measure how much value is successfully created, or determine whether the IT strategy is aligned with business strategy, or find out if the IT organization has a strategy that focuses on creating business value. Innovation Value of Institute (IVI) introduces a new concept known as the IT Capability Maturity Framework (IT-CMF) which can help IT organizations to align the business vision with the IT vision so that IT strategy could focus on value creation. the IT-CMF implementation which begins with the assessment of the maturity of IT organization can provide an overall picture, so that organization can prioritize the development of appropriate IT investments to support the value creation for the overall business.
\end{abstract}

Keywords: IT, Value, Competitive Advantage, Inovation, IT Organization, IVI, IT-CMF

\begin{abstract}
ABSTRAK
Investasi Teknologi Informasi atau Information Technology (IT) yang diharapkan dapat memberikan value kepada bisnis melalui perannya sebagai keunggulan kompetitif dan penciptaan inovasi selalu menjadi tujuan utama dari pelaku bisnis. Namun demikian, tidak mudah untuk mengukur seberapa besar value yang berhasil diciptakannya, atau memastikan apakah strategi IT sudah sejalan dengan strategi bisnis, atau mengetahui apakah organisasi IT sudah menjalankan strategi yang memfokuskan kepada penciptaan value bagi bisnis. Innovation Value of Institute (IVI) memperkenalkan sebuah konsep baru yang dikenal dengan nama IT Capability Maturity Framework (IT-CMF), yaitu sebuah framework yang dapat membantu organisasi IT di dalam me-align visi bisnis dengan visi IT sehingga strategi IT dapat difokuskan kepada value creation. Implementasi IT-CMF yang diawali dari assesment terhadap maturity organisasi IT dapat memberikan suatu gambaran menyeluruh sehingga organisasi dapat memprioritaskan pengembangan investasi IT yang tepat untuk mendukung penciptaan value bagi bisnis secara menyeluruh.
\end{abstract}

Kata kunci: IT, Value, Keunggulan kompetitif, Inovasi, Organisasi IT, IVI, IT-CMF 


\section{PENDAHULUAN}

Artikel Nicholas Carr yang berjudul IT Doesn't Matter (2007) menimbulkan berbagai komentar di kalangan pemimpin bisnis dan profesional IT. Harvard Business Review (HBR) sampai mengeluarkan sebuah ringkasan berjumlah 17 halaman untuk membahas topik ini dengan judul Does IT Matter? (Juni 2003). Artikel HBR ini menuliskan bahwa pada dasarnya, Carr tidak benar-benar mengatakan bahwa teknologi informasi adalah sama sekali tidak berguna. Di dalam artikelnya, Carr (2003) mengatakan bahwa bisnis telah melebihi perkiraan dalam menilai strategic value dari IT. Mereka juga sudah mengeluarkan lebih banyak di dalam mengembangkan IT dengan harapan dapat memanfaatkan IT sebagai strategic advantage sehingga memberikan value kepada bisnis. Pengembangan IT sampai kepada merubah platform dimana bisnis sangat tergantung dengan IT. IT digunakan di setiap lini perusahaan setiap harinya, sehingga perusahaan harus mengeluarkan biaya yang tidak sedikit di dalam mengatur infrastruktur, aplikasi, sampai harus memikirkan aspek keandalan, keamanan, dan ketersediaan layanan yang diberikan IT. Dari semua upaya tersebut, IT belum tentu menjadi sebuah katalis di dalam menciptakan dan mendukung diferensiasi strategis seperti yang diharapkan.

Artikel HBR (2003) menuliskan bahwa judul yang digunakan Carr (2003) mungkin dapat menjadi perhatian para pembacanya, tetapi juga sangat potential membuat para pembacanya "tersesat" dalam memahami value yang diberikan oleh IT. Selanjutnya artikel HBR (2003) menuliskan bahwa IT menjadi strategis karena dampak tak langsungnya, IT menciptakan beberapa kemungkinan dan pilihan yang belum ada sebelumnya. Perusahaan yang dapat melihat dan bertindak dengan memanfaatkan kemungkinan-kemungkinan baru ini sebelum dimanfaatkan perusahaan lain, akan terus menerus dapat memberikan layanan yang "lain dari yang lain" dalam memenangkan kompetisi pasar.

Artikel HBR (2003) berasal dari surat John Seely Brown (mantan Chief Scientist Xerox) dan Hagel III. John (management consultant) menuliskan beberapa pelajaran sebagai hikmah pembelajaran dari kegagalan IT saat memberikan value di masa lalu, yaitu: (1) Mengekstrak nilai dari IT memerlukan inovasi dalam praktik bisnis; (2) Dampak Ekonomi IT berasal dari inovasi yang lebih bukan inisiatif big bang; (3) Dampak strategis investasi IT berasal dari efek kumulatif dari inisiatif berkelanjutan untuk melakukan inovasi praktek bisnis dalam waktu dekat. Untuk menjawab komentarkomentar terhadap tulisannya, Carr (2003) menuliskan bahwa dia setuju bahwa banyak perusahaan sudah merasakan manfaat dari penggunaan IT di dalam menciptakan diferensiasi untuk mengungguli kompetitornya, tetapi bukan berarti bahwa sistem yang terlibat dalam mengatur proses dan informasi tersebut hanya satu-satunya sumber yang menciptakan value tersebut. Carr menambahkan bahwa sudah saatnya perusahaan dapat melihat bahwa layanan yang diberikan IT bersifat umum. Oleh karena itu, fungsi IT sangat dengan mudah dan cepat ditiru dan dijalankan oleh competitor. Dengan demikian, semakin terikat sebuah competitive advantage dengan teknologi, competitive strategy itu akan semakin tidak menjadi bersaing pada akhirnya.

Dengan kondisi demikian, sudah seharusnya perusahaan memperlakukan IT seperti komoditas lainnya. Sehingga perusahaan dapat mencapai suatu tingkat kmpetitif dengan resiko dan biaya terendah. Dari paparan di atas, kita dapat melihat bahwa argumentasi yang dilakukan pada hampir 10 tahun yang lalu mungkin masih valid dan masih menjadi pertanyaan di kalangan pelaku bisnis. Keraguan terhadap apakah IT dapat memberikan value seperti yang diharapkan, apakah investasi yang dikeluarkan sudah sepadan dengan benefit yang didapat, sampai pada apakah IT memang benar-benar spesial (menciptakan competitive advantage) menjadi tantangan para pemimpin dan profesional IT seperti CIO, IT Director, dan IT Manager.

Lalu apakah ada tools yang dapat menilai value dari sebuah IT? apakah ada framework yang dapat mengarahkan pelaku bisnis dan profesional IT sehingga dapat menciptakan strategi IT yang 
benar-benar dapat memberikan value kepada bisnis ? Tulisan ini selanjutnya akan membahas sebuah framework yang diperkenalkan oleh Innovation Value Institute (IVI) yang dikenal dengan nama IT Capability Maturity Framework (IT-CMF).

\section{METODE}

Tulisan ini menggunakan metode penelitian literatur yang berasal dari Framework IT-CMF yang dikembangkan oleh IVI, jurnal HBR, dan Artikel Boston Consulting Group (BCG).

\section{HASIL DAN PEMBAHASAN}

Dalam websitenya IVI menuliskan bahwa mereka melakukan riset dan membangun framework dan roadmap bagi IT dan eksekutif bisnis untuk menciptakan value yang lebih dari IT, dan dapat memberikan inovasi IT. Cakupan dari IT business value framework yang dikembangkan oleh IVI berfokus pada IT value dan inovasi IT dan akan mengembangkan metodologi alat dan praktik sehingga perusahaan dapat mengatur IT capability mereka secara optimal untuk meningkatkan value yang diberikan oleh IT dan IT driven innovation.

Framewok yang dikembangkan oleh IVI ini adalah IT Capability Maturity Framework (ITCMF). Agerbak dan Deutscher (2011) dalam tulisannya yang berjudul Managing IT for Business Value, menyebutkan bahwa IT-CMF ini dihasilkan dari 60.000 jam RnD dan investasi lebih dari USD 10 juta. IVI website menyebutkan bahwa pada saat ini (2011) keanggotaan dari IVI, adalah sebagai berikut:

Tabel 1

Keanggotaan IVI

\begin{tabular}{|c|c|c|c|}
\hline Steering Patrons & Patrons & Contributors & Associates \\
\hline $\begin{array}{l}\text { National University of Ireland, } \\
\text { Maynooth } \\
\text { Intel } \\
\text { The Boston Consulting Group }\end{array}$ & $\begin{array}{l}\text { British Petroleum } \\
\text { Chevron } \\
\text { Cisco } \\
\text { Ernst and Young } \\
\text { Microsoft } \\
\text { SAP }\end{array}$ & $\begin{array}{l}\text { AirTricity } \\
\text { Aupec } \\
\text { AXA Technology Services } \\
\text { BearingPoint } \\
\text { Bord na Mona } \\
\text { Centre for Software Engineering } \\
\text { Compugen } \\
\text { ESB } \\
\text { ExxonMobil } \\
\text { Gartner EXP } \\
\text { Fingal County Council } \\
\text { HEAnet } \\
\text { iSite Solutions } \\
\text { Logica } \\
\text { Mainstream Renewable Power } \\
\text { Merck } \\
\text { Mitovia } \\
\text { Nexen } \\
\text { SAS Institute } \\
\text { Gaelstorm } \\
\text { Sumerian } \\
\text { Xilinx }\end{array}$ & $\begin{array}{l}\text { AIM Ireland } \\
\text { Beaumont Hospital } \\
\text { Butler Group } \\
\text { CEPIS } \\
\text { Cranfield University } \\
\text { Dublin City University } \\
\text { ICT Ireland } \\
\text { Institute of Technology, } \\
\text { Blanchardstown } \\
\text { IT@Cork } \\
\text { NUI, Galway } \\
\text { Project Management Institute } \\
\text { (Ireland Chapter) } \\
\text { University of Bonn-Rhein-Sieg } \\
\text { University of Limerick }\end{array}$ \\
\hline
\end{tabular}

McSweeney (2011) mengatakan bahwa 62\% organisasi mengatakan bahwa mereka kesulitan menghitung ROI investasi IT; $45 \%$ organisasi mengatakan bahwa business value metric mereka pada saat ini tidak dapat secara akurat "menangkap" value dari investasi IT; $52 \%$ organisasi mengatakan 
bahwa para eksekutif bisnis skeptis di dalam melihat usaha untuk menghitung bisnis value; dan hanya $41 \%$ organisasi yang melakukan Return on Investment Analysis terhadap IT bujetnya. Survey di atas menunjukan perhatian dari para pelaku bisnis terhadap value dari investasi IT terhadap bisnisnya yang masih kurang sesuai dari harapan mereka.

Dorongan seperti yang dipaparkan di atas membuat beberapa institusi akademisi, perusahaan, sampai pemerintah melakukan riset di area tersebut. IT-CMF bermula dari gabungan antara riset yang dilakukan oleh akademisi, praktik-praktik dari industry-industri yang sudah terbukti, dan juga dari pengalaman Intel di dalam melakukan transformasi di IT organisasinya. Kekurangan framework yang ada pada saat itu, dan pertanyaan-pertanyaan yang diajukan para pemimpin bisnis terhadap masalah ini mendorong pembentukan framework IT-CMF di dalam INTEL yang kemudian dikembangkan oleh riset yang dilakukan oleh IVI.

IVI adalah global consortium yang terdiri dari organisasi non profit, pemerintah, dan akademisi yang dibentuk pada tahun 2006 antara Intel, Boston Consulting Group dan University of Ireland Maynooth, dengan tujuan untuk membentuk sebuah standar dalam mengatur IT business value. Pada 2 juni 2010, IT-CMF versi 1.0 diluncurkan oleh IVI. IVI menuliskan bahwa IT Capability Maturity Framework dapat menunjukan bagaimana mengembangkan definisi dari business value dari produktifitas, menunjukan bagaimana organisasi dapat mengukur business value dari sebuah investasi IT, memilih proposal investasi IT yang tepat, memberikan competitive advantage dan mengatur investasi IT dengan tujuan mengoptimalkan value yang dihasilkannya bagi bisnis.

Agerbak dan Deutscher (2011) dalam tulisannya menyebutkan bahwa IT-CMF merupakan framework yang terbentuk dari IT Framework yang sudah ada, seperti Capability Maturit Model Integration (CMMI), Control Objectives for Information and related Technology (COBIT) dan Information Technology Infrastructure Library (ITIL). Yang membedakan adalah bahwa IT-CMF menggunakan pendekatan holistik dengan mencakup semua aktifitas IT di dalam sebuah framework, dan menggunakan sebuah metodologi yang konsisten. Selain itu, IT-CMF menekankan pada pemberian secara nyata hasil yang kuantitatif dan pengembangan business value.

McSweeney (2011) mengatakan bahwa IT CMF objektif adalah: (1) Menilai praktik saat ini; (2) Memahami kesempatan dan value increasing maturity; (3) Menjembatani kesenjangan struktural dalam kerangka penilaian lainnya.

Jadi bagaimana IT-CMF bekerja? IVI menjelaskan bahwa konsep dasar dari IT-CMF adalah empat strategi berkaitan, yaitu: (1) Managing IT like a Business 'menjalankan IT seperti unit bisnis lainnya'; (2) Managing the IT Budget 'mengatur bujet IT'; (3) Managing the IT Capability 'mengatur kemampuan IT'; dan (4) Managing IT for Business Value 'mengatur IT untuk Value bisnis (Gambar $1)$.

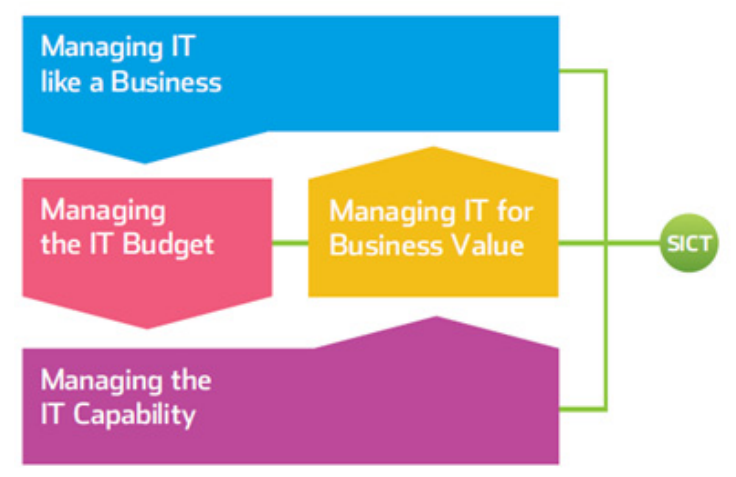

Gambar 1. IT-CMF Four inter-related strategies. Sumber: IVI 
Setiap strategi di dalam IT-CMF tersebut memiliki 5 maturity level (Gambar 2), yang memudahkan organisasi untuk melakukan assesment terhadap level maturity dari IT organisasi terhadap kelima strategi IT-CMF, sehingga organisasi dapat membuat perencanaan untuk meningkatkan maturity tersebut untuk meningkatkan proses di dalam menjalankan strategi IT. Pada akhirnya value bisnis dapat dihasilkan seperti yang diharapkan, seiring dengan meningkatkan maturity level dari keempat strategi IT-CMF.

Di dalam situsnya IVI memberikan sample assessment 'contoh penilaian', di mana organisasi dapat melihat maturity level organisasi IT-nya pada saat ini (Gambar 3). Contoh hasil analisis yang lebih menyeluruh terhadap IT-CMF maturity level (Gambar 4) diberikan oleh Agerbak dan Deutscher (2011). Di dalam grafik bisa dilihat area mana saja yang merupakan kesempatan potensial untuk dikembangkan di dalam meningkatkan value bisnis, juga area mana saja yang menjadi tidak menguntungkan karena investasi berlebihan.Oleh karena itu, organisasi dapat meluruskan strategi ITnya dengan mengalokasikan investasinya ke area yang lebih dapat menghasilkan value, dan memprioritaskan pengembangan di area tersebut. Patokan didapat dari industri rata-rata yang sama atau yang dapat mewakili sebagai referensi pembanding. Sedangkan penjelasan detail variabel ke empat strategi berkaitan dan IT-CMF dapat di lihat pada Gambar 5, yang diadaptasi d ari rangkuman yang dibuat oleh Agerbak dan Deutscher (2011).

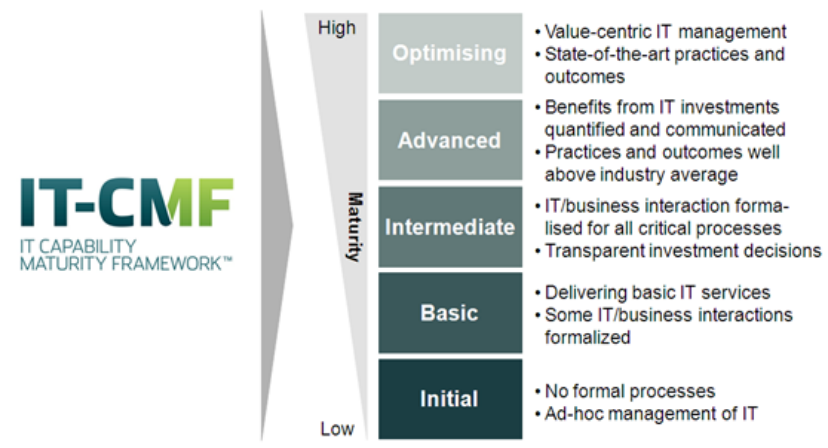

Gambar 2. Maturity Level of IT-CMF strategies.

Sumber: IVI

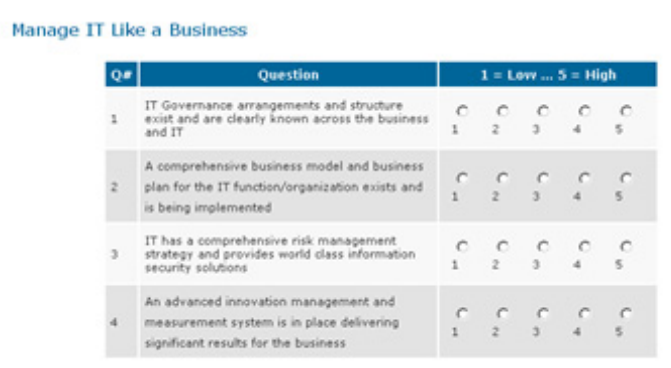

Manage the Ir Budget
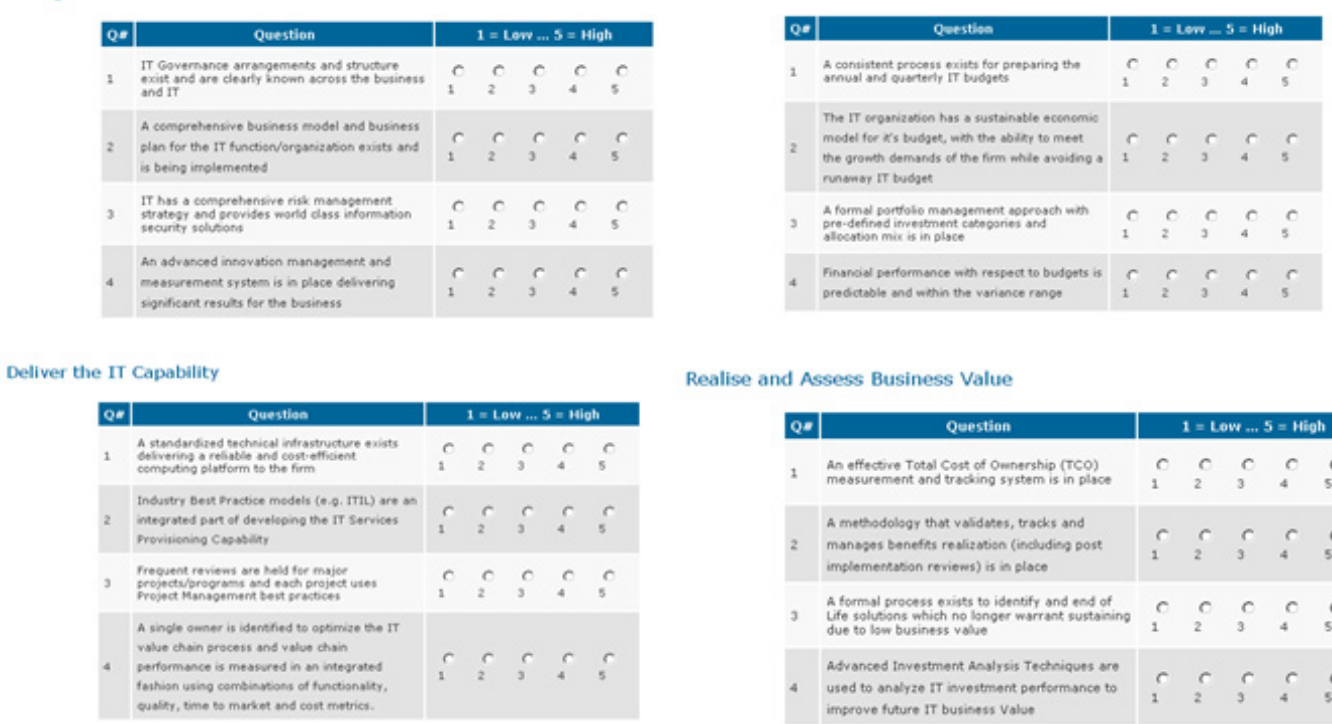

Realise and Assess Business Value

Gambar 3. Contoh penilaian IT-CMF maturity level. Sumber: IVI 


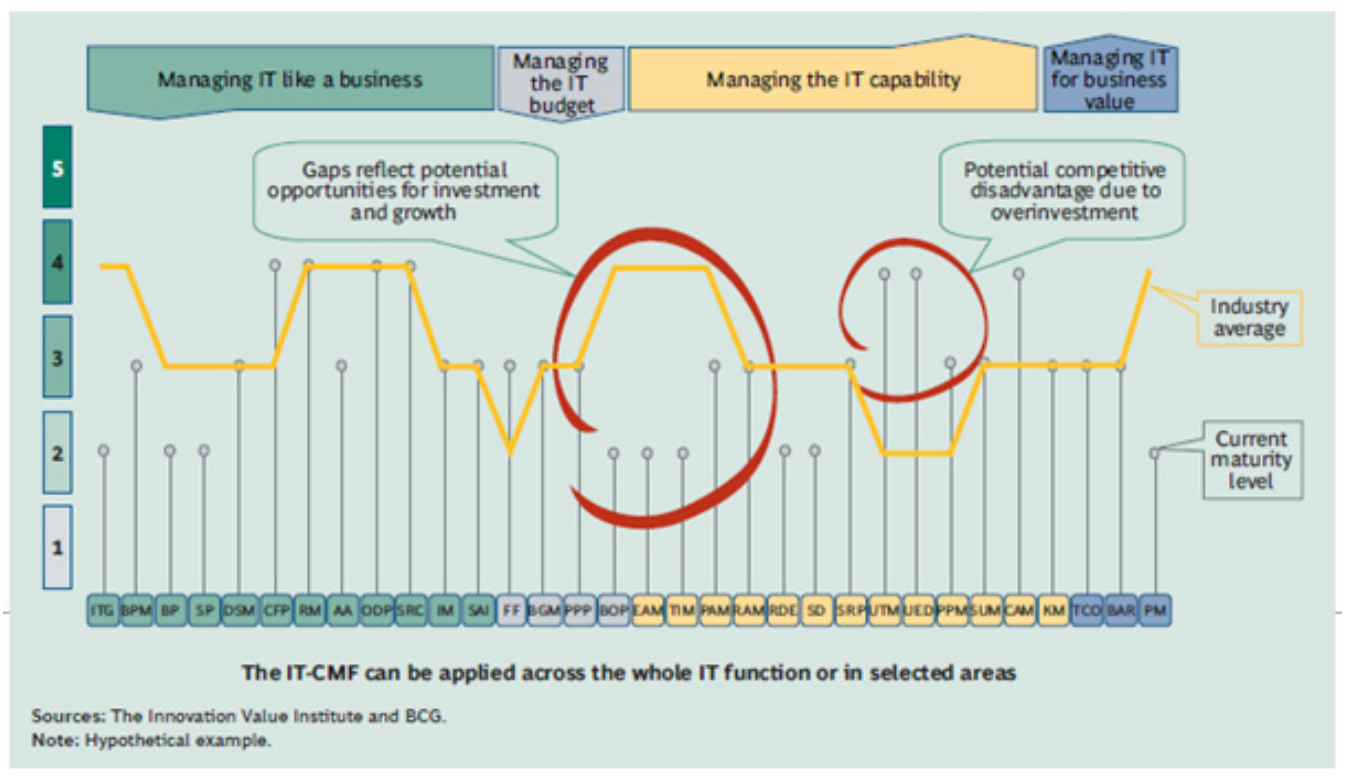

Gambar 4. IT-CMF assessment output.

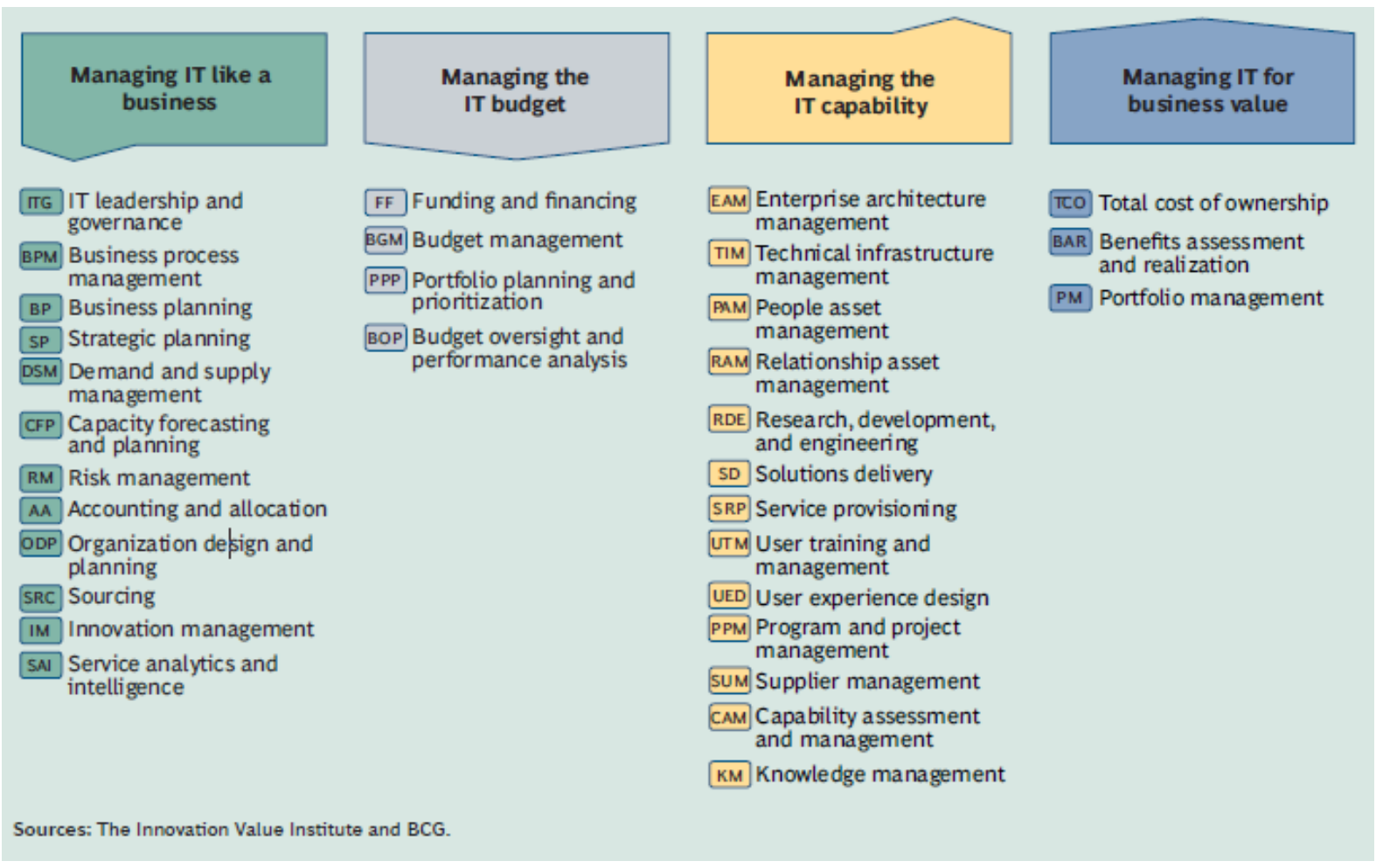

Gambar 5. IT-CMF assesment output.

Ada 12 komponen strategis dalam menjalankan IT seperti unit bisnis lainnya, seperti IT leadership \& governance, business process management, business planning, strategic planning, demand \& supply management, capacity \& supply management, risk management, accounting \& allocation, organization design and planning, sourcing, innovation management dan service analytics \& intelligence. Ke-12 komponen ini diharapkan dapat mampu membawa fokus strategi IT yang 
berawal dari teknologi dan produksi kepada pelanggan dan layanan. Proses transformasi di dalam menjalankan IT organisasi seperti bisnis unit lain pada umumnya selesai jika IT sudah berubah dari mengeluarkan biaya menjadi value centre. Pendanaan dan pembiayaan, manajemen anggaran, perencanaan dan prioritas portofolio, pengawasan anggaran, dan analisis kinerja merupakan komponen-komponen dari mengatur bujet IT. Strategy ini menjadi penting bagi organisasi dalam mengatur budjet IT, sehingga dapat mereduce cost dan mengalokasikan fund kepada solusi IT yang inovatif yang dapat memberikan value dan kinerja yang lebih baik.

Sedangkan mengatur kemampuan IT adalah mengatur kemampuan organisasi IT dalam memberikan layanan bisnis, mengatur aset-aset IT melalui rantai value dan mengembangkan kompetensi pokok. Pengaturan kemampuan IT yang benar akan membawa perkembangan berkesinambungan pada aplikasi strategis baru untuk memberikan keuntungan ekonomi berkelanjutan.

Dan mengatur value bisnis IT berarti menekankan kepada hasil dari investasi IT kepada keuntungan bisnis keseluruhan. Di dalam IT-CMF disediakan tools untuk mengukur value bisnis, seperti total cost of ownership (TCO), return on investment (ROI), the business value index (BVI) dan portfolio management. Strategi ini menyediakan struktur untuk organisasi IT agar berubah dari 'mengatur IT sebagai poyek teknologi' menjadi 'IT sebagai portfolio dari sebuah investasi yang dapat menghasilkan value bisnis'.

\section{PENUTUP}

IT-CMF sebagai framework yang dapat membantu untuk "meluruskan" organisasi IT dengan visi dan tujuan dari bisnis merupakan suatu terobosan. Penciptaan value bisnis yang diawali dari penilaian terhadap kondisi organisasi IT, evaluasi terhadap prioritas dan fungsi kontrol kepada investasi IT, sampai kepada pengembangan terhadap inovasi yang ada pada empat strategi berkaitan dapat memberikan jawaban atas bagaimana mengatur dan memberikan value dari IT. Namun demikian studi literatur lebih mendalam mengenai detail IT-CMF, implementasi IT-CMF pada organisasi IT nyata dan evaluasi hasil dari implementasi perlu terus dikaji ulang, serta apakah framework ini benarbenar dapat membantu dalam menjawab pertanyaan-pertanyaan diatas.

\section{DAFTAR PUSTAKA}

Brown, John Seely. (2003). Does IT Matter?. Diakses dari http://www.johnseelybrown.com/Web_Letters.pdf.

Carr, Nicholas G. (2007). IT Doesn't Matter. Diakses dari http://www.nicholasgcarr.com/articles/matter.html

Innovation Value Institute. (2010). Current Consortium Membership. Diakses dari http://ivi.nuim.ie/membership/members.shtml

Innovation Value Institute. (2010). IT-CMF Introduction. Diakses dari http://ivi.nuim.ie/ITCMF/\#

Innovation Value Institute. (2010). Understanding the Framework. Diakses dari http://ivi.nuim.ie/ITCMF/understanding.shtml

Mcsweeney, Alan. (2011). Using the IVI IT-CMF to Develop a Business-Oriented Information Technology

Strategy.

Diakses

dari 
http://www.authorstream.com/Presentation/alanmcsweeney-770014-using-the-it-cmfframework-to-develop-business-oriented-strategy/

The Boston Consulting Group. (2010). Managing IT for Business Value: the New Gold Standard. Diakses dari http://www.bcg.com/documents/file60624.pdf.

The Boston Consulting Group. (2010). Technology-Enabled Innovation: a Weapon to Win the Battle for Competitive Advantage. Diakses dari http://www.bcg.com/documents/file50205.pdf. 